It would appear that the Uvæan Parrakeet, of which we now give an illustration (Fig. 3I), taken from one of the Zoological Society's living specimens, is a kind of satellite of the New Caledonian Parrakeet, as is the small island of Uvéd, in which it is found, of the larger island of New Caledonia. Mr. Layard had a living pair of the Uvean bird for some time in his possession before he noticed their difference from the New Caledonian bird, of which he had regarded them as the immature form. But in the first place the crest of the two birds is totally different. In Nymphicus cornutus the crest is composed of two elongated feathers, which are black, faintly tinged with green, and broadly tipped with red. In N. uvceensis, as will be seen in our figure, the crest consists of a bunch of about six short, upturned, entirely green feathers, springing from the end of a small spot of red which occupies the centre of the forehead. In $N$. cornutus the two long crest-feathers rise from the centre of the broad red cap which covers the whole top of the head. Besides this difference the former bird does not present the broad orange nuchal collar which ornaments $N$. cornutus, and exhibits only the faintest trace of orange on the rump.

The small island of Uvéa, one of the Loyalty group, to which the new species is confined, consists, as $\mathrm{Mr}$. Layard tells us, of a series of small islets joined together by a connecting reef with a lagoon in the centre. It is very singular that this distinct form should be found only in so restricted a locality, while its near relative, the "Horned Parrot" of Cook, appears to be distributed all over the large island of New Caledonia.

\section{THE ELECTRIC LIGHT AT THE SAVOY THEATRE}

MR. D'OYLY CARTE, having determined to light $\mathrm{I}$ the Savoy Theatre by the Swan incandescence electric light, intrusted the work of installation to Messrs. Siemens Brothers and Co. The theatre is lighted by no less than II94 Swan lights of the improved form introduced by Mr. C. H. Gimingham, of the Swan United Electric Light Company. Of these II94 electric lights, the auditorium is lighted by 150 lamps attached in groups of three, supported on threefold brackets projecting from the different tiers and balconies, each lamp being inclosed within a ground, or opaloid, shade, by which arrangement a soft and pleasant light is produced. These bracket lamp-holders have been designed and constructed by Messrs. Faraday and Son, of Berners Street, London.

Two hundred an 1 twenty lamps are employed for the illumination of the numerous dressing-rooms, corridors, and passages belonging to the theatre, while no less than 824 Swan lamps are employed for the lighting of the stage.

The stage lights are distributed as follows :-

\begin{tabular}{|c|c|c|c|c|c|c|}
\hline & 50 & 100 & s ea & above the stage & $\ldots$ & 600 \\
\hline $\mathbf{I}$ & ", & 60 & ," & & $\ldots$ & 60 \\
\hline 4 & ," & I 4 & , & fixed upright $\ldots$ & $\ldots$ & 6 \\
\hline 2 & ", & 18 & ", & " & $\cdots$ & \\
\hline 5 & $"$ & 10 & ", & ground lights & $\cdots$ & \\
\hline 2 & " & 11 & " & ", & $\cdots$ & $2+2+2$ \\
\hline
\end{tabular}

In addition to the above-mentioned lights within the theatre, there are eight pilot lights in the engine-room, which, being in the same circuit with some of the lights in the theatre, serve the purpose not only of illuminating the machinery, but also of indicating to the engineer in charge of the machines, by the changing of their illuminating power, when the lights in the building are turned up or down.

The lamps are at present worked in parallel circuit in six groups, five of which comprise 200 lamps each, and the sixth 202 lamps. The current of each group is produced by one of Messrs. Siemens Brothers and Co.'s $\mathrm{W}_{1}$ alternate current machines, the field magnets of which are excited by a separate dyna mo electric machine of the Siemens type, known as $D_{7}$. The machines and engines are fixed in a shed erected on a piece of waste land adjacent to the Victoria Embankment, the current being conveyed to the theatre by means of insulated cables laid underground.

The six alternate or $W_{1}$ machines are driven at a speed of 700 revolutions per minute, and the six exciting or $\mathrm{D}_{7}$ machines at 1150 revolutions, by three steam-engines, that is to say, a portable 2o-horse engine by Garrett, a I2-horse power portable by Marshall, and a 20-horse semi-portable engine by Robey, but the power actually utilised, as measured by a "von Hefner Alteneck" dynanometer, is between 120 and 130 horse-power. We must not, however, omit to state that, in addition to the six pairs of machines for working the $\mathrm{I} 2 \mathrm{O} 2$ incandescent lamps, there is also a $\mathrm{D}_{2}$ Siemens dynamo machine for producing the powerful arc electric light suspended outside the theatre, and over the principal entrance in Beaufort Buildings, and that the power to drive this machine is included in the above-mentioned horse-power employed, as well as that necessary for driving the shunt machine used to charge the secondary batteries for the fairy lamps.

The most interesting feature, however, from a scientific point of view, of this most interesting installation, is the method by which the lights in all parts of the establishment are under control, for any of the series of lights can in an instant be turned up to their full power or gradually lowered to a dull red heat as easily as if they were gas lamps, by the simple turning of a small handle. There are six of these regulating handles, corresponding to the number of the machines and circuits-arranged side by side against the wall of a small room on the left of the stage, and each handle being a six-way switch, can, by throwing into its corresponding magnet-circuit greater or less resistance (according to its six stages), lessen or increase the strength of the current passing through the lamps by as many grades. The special interest of this part of the installation, however, is the fact that the turning down of the lights is accompanied by a corresponding saving of motive power in the engine, for the variable resistance which is controlled by the regulators is not thrown into the external or lamp circuit of the alternate current machines, but into the circuit by which their field magnets are excited.

The fittings of the lamps in the passages, staircases, \&c., have, up to the present, been of a temporary nature, but, as the electric lighting has worked to the entire satisfaction of all concerned, these temporary fittings will now be replaced by permanent brackets, quite independent of the gas brackets.

All risk of fire is avoided by the leading wires being thoroughly insulated, and small pieces of lead wire being inserted into the circuit wherever a branch wire leaves the mains. These "safety-pieces" of lead are chosen of such size that they will melt before the conductors themselves become sufficiently heated to cause any danger, and by their melting the current is at once interrupted.

The small lamps worn by the fairies, and which have been specially made by the Swan United Electric Light Company, are rendered incandescent by the current produced from a small "secondary" battery, which is carried on the back like a small knapsack. These secondary batteries have been made by Messrs. Siemens Brothers and Co. on a new plan, and are charged by a shunt-wound Siemens' dynamo in the engine-shed. Each battery is provided with a switch, by means of which the light can be turned on or off by the wearer at pleasure.

The system of electric lighting has now been working 
at this theatre for about a year and a half without any accidents, and has proved to possess many advantages over gas as applied to the illumination of buildings of this description. Not the least amongst these are the total absence of heat and vitiated air in the house, and the length of time during which the decorations will retain their freshness and colour instead of becoming quickly faded and tarnished, as would be the case were the old system of gas adopted.

\section{ON THE NATURE OF INHIBITION, AND THE ACTION OF DRUGS UPON IT}

$\mathrm{BY}$ inhibition we mean the arrest of the functions of a structure or organ, by the action upon it of another, while its power to execute those functions is still retained, and can be manifested as soon as the restraining power is removed.

It is thus distinguished from paralysis, in which the function is abolished, and not merely restrained.

Inhibition is c ne of the most perplexing problems in physiology, and we have at present no satisfactory hypothesis regarding it. It plays, however, such a very important part in pharmacology, that we cannot pass it over; and as it is through the action of drugs upon the various functions of the body that we bave already arrived at a knowledge of inbibitory actions, which would otherwise have been impossible-as, in fact, pharmacology has here quite outstripped physiology-we are obliged to enter into some hypothetical considerations, in order to be able to form some kind of idea regarding the mode of action of many drugs.

Hypotheses serve as "pegs on which to hang facts," and by their aid the isolated facts which few memories could carry may be arranged, and their relation to each more readily perceived. A hypothesis serves also as a guide for furiher experiments, by which it may be either disproved or supforted. Should facts be against it, so much the worse for the hypothesis; it must be discarded, and another tried in its place; but if facts agree with it we obtain a means of predicting phenomena, and make another step in knowledge. Like other useful things, hypotheses are not without danger, and sometimes do harm by satisfying people and stopping further inquiry. Thus Sultzer noticed the peculiar taste produced by the contact of two dissimilar metals with each other and with the tongue forty years before Galvani; but at that time the-doctrine of vibrations was employed to explain all natural phenomena, and he concluded that some peculiar vibration occurred fr $\mathrm{m}$ the contact of the metals, which produced the peculiar sensation on the tongue. All the world were satisfied with the explanation, and thus a prominent fact slept in obscurity from the time of Sultzer to that of Galvani, no further attempts being made to determine the nature of the vibrations or the laws which governed them. ${ }^{1}$ Yet in their proper place hypotheses are most useful, and but for the hypothesis that light, heat, and sound are due to waves, our knowledge of their phenomena would be much less than it is.

The cases of inhibition, as we may term them, which we meet with in the study of physics, are the production of complete silence by the interference of two sounds and of darkness by the interference of two rays of light.

When two sounds or two rays of light are combined, so that the crests of the waves of which they consist coincide, the sound becomes louder and the light brighter. If they are thrown together, so that the crests of tbe waves in the one sound or ray coincide with the sinuses or hollows of the other, they completely counteract each other, and silence or darkness is produced.

When the waves are of different rhythms, the crests and hollows of the two sounds or rays, which at one time coincide, will gradually interfere, and again gradually

\footnotetext{
"Ree's Cyclopedia, Article "Galvanism."
}

coincide, so that rhythmical alternations of loud sound and silence, of bright light and darkness, are produced.

A good example of interference or physical inhibition, and one that affords an illustration well suited to our purpose, is that of Newton's rings. When a lens of small curvature is placed on a plane surface of glass, a series of rings is observed, starting from the centre of the lens and passing concentrically outwards. If monochromatic light is used, such as pure yellow light, fure red light, \&c., these rings are alternately bright and dark; but if white light is used, they appear as a number of circular bands of different rainbow colours. The cause of these rings is, that though the surface of the lens appears to the eye to be in contact with the plate of glass over a considerable area, it is not really so; a very fine film of air of varying thickness being interposed between them.

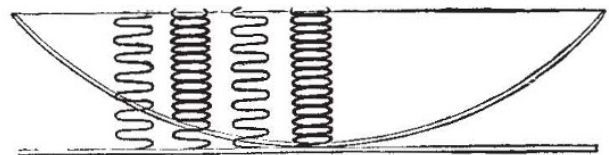
FiG. I.-A very diagrammatic represt ntation of interference in Newton's

When a ray of light passes through the lens on to the glass, part of it is reflected back from the lower surface of the lens, and part of it from the upper surface of the glass plate. Between those two points there is a very minute film of air: one ray has therefore to travel somerwhat further than the other. The distance which it has to travel is only through the extremely thin layer of air lying between the surface of the lens and the glass and back again ; but this distance at some places is just sufficient to throw the waves in the one beam half a wave-length behind those in the other, and to produce darkness by their interference.

As we recede from the point of most complete contact between the lens and the glass, the thickness of air increases, the ray has somewhat further to travel, and the distance is then just sufficient to throw it $a$ whole wavelength bebind the other ray; no interference is produced, and we get a ring of bright light.

Further outwards the increased thickness of the film of air is again sufficient to throw one ray $a$ wave-length and a half behind its fellow; interference is again produced, and darkness is the result.

With rays, then, of one colour, or of one wave-length, we get alternately light and darkness by interference.

But it is evident that the extra distance which the waves have to travel in order to produce interference will not be the same for long and short waves; and thus it is found that when white light, which contains rays of different wave-lengths, is used, the rings, instead of keing alternately light and dark, are coloured.

The very distance which was sufficient to throw the red rays half a wave-length behind the other, and to produce interference, will throw, let us say, the violet rays a whole wave-length behind, and thus there will be no interference and vice vers $\hat{a}$; the distance which causes interference of the violet rays does not cause interference of the red, and so on with other colours.

Thus the spaces which would have been perfectly dark when rays of pure red or pure violet, or more correctly ultra-violet, were used, would be filled up by the other if used together, and when white light is used, the various waves interfere at different places, and so we get a series of rainbow colours.

The extra distance which one beam has to travel in order to produce interference with another is not absolute, but relative to the wave-length. This relation differs for different wave-lengths, and therefore if the relative distances remain constant, the effect of the beams on each other will vary if their wave-lengths be changed.

It is obvious that if both the wave-lengths and the 